\title{
New Biofuels Industry: Biomass Availability and Supply Chain
}

\author{
David J. Parrish
}

Published online: 27 March 2009

(C) Humana Press 2009

This session focused on practical supply chain questions for biomass feedstocks, e.g.,

- Availability: How much feedstock is available?

- Properties: What are the properties of different feedstocks?

- Supply chain:

$\circ$ What are the issues with harvesting, handling, storage, and transportation?

$\circ$ How much area is needed to source a scale facility?

Biomass Availability This was addressed through both oral presentations and posters. An update was given on the Billion-Ton Resource Assessment report by Bob Perlack. The original report was published in 2005 and estimated the current and potential availability of biomass feedstocks. The potential was projected as approximately 1.3 billion tons and was what might be reasonably available around midcentury when large-scale biorefineries are likely to exist. The report emphasized primary sources of forest- and agriculture-derived biomass such as logging residues, fuel treatment thinnings, crop residues, and perennially grown grasses and woody crops. These primary sources have the greatest potential to supply large sustainable quantities of biomass. Since publication of the Billion-Ton Resource Assessment, follow-up efforts have focused on updating the results, disaggregating the resource potential to counties and fine spatial scales, examining how the resource potential is affected by environmental sustainability, and answering questions involving what feedstocks will be used, when will they be used, what will be the costs, and what will be the economic impacts. Answers to these latter questions are focused on nearer-term time periods coincident with implementation of the Energy Independence and Security Act.

Michael Blaylock highlighted corn stover as a potential biomass feedstock for cellulosic ethanol. Currently grown on more than 93 million acres in the USA and annually yielding 300 million tons of biomass that could produce up to about 25 billion gallons of cellulosic ethanol, its planting, cultivation, and harvesting costs can be shared with a popular cash

D. J. Parrish $(\bowtie)$

Crop and Soil Environmental Sciences, Virginia Tech, Blacksburg, VA 24061, USA

e-mail: dparrish@vt.edu 
crop, corn grain. As a domesticated crop, it is easy to grow and accepted by agricultural producers. Numerous other benefits include well-understood capabilities for bioengineering and breeding and the lack of wild relatives with which it is likely to crossbreed. Surging demand for corn grain as an ethanol feedstock, however, has increased scrutiny of potential drawbacks and risks of using corn stover as a biomass feedstock. Removing too large a fraction of the stover from the field, for example, could reduce soil moisture or organic carbon below desired levels, decreasing soil fertility and crop yields over time. Higher water and fertilizer inputs required for increased biomass yields could add to environmental stresses.

Properties Several herbaceous species have been studied for their potential as herbaceous biomass feedstocks as discussed by Dave Parrish, but the broader focus of this presentation was on characteristics of an ideal, or ideotype, feedstock. Those desirable traits include being readily bioengineered and perennially productive, having minimal antiquality factors, not being weedy/invasive, being readily established (using no-till methods, preferably), having flexible harvests and no or few pests, being drought- and heat-tolerant, having low input requirements, et al. Among strong candidates, Switchgrass (Panicum virgatum) is another potential feedstock as presented by Steve Fransen. Switchgrass cultivars have been grown under research conditions for biofuel in the Pacific Northwest (PNW) since 2002. Research in the PNW is needed to identify other planting windows without stand loss due to winterkill. Dacotah and Nebraska 28, the earliest maturity cultivars, easily produce two biomass crops per season. Intermediate varieties such as Trailblazer, Forestburg, Cave-in-Rock, Blackwell, and Shawnee will produce two excellent biomass harvests with one harvest slightly less mature. Early maturing upland switchgrass transitioned into fall dormancy in late September. Intermediate upland varieties transition about 2 weeks later than early varieties with the late lowland varieties transitioning into fall dormancy last. Biomass yields and quality were compared among a full range of switchgrass variety maturities grown in the PNW.

Supply Chain This is for forest biomass such as agricultural or woody residues. Supply chain involves tradeoffs of productivity, production, transportation, and capital costs, as presented by Sudhagar Mani. Forest residues including logging residues and understory biomass are a potential source of fuel for biofuels production, if they can be economically harvested and transported to the end user. Most forest residues are currently burned or left in the field after timber harvesting. At present, forest residues are the only untapped sources of biomass from forestlands and the economics of harvesting and transporting these residues were shown to be very important. Several studies have been conducted to assess the sources of residues available from forestlands. However, there is little information available on the actual cost of harvesting and transport of forest residues for bioenergy production. A real-time simulation and modeling of forest residue harvesting, collection, and transport operations was used to evaluate tradeoffs. The model is an extension of the current Department of Energy/Oak Ridge National Laboratory Integrated Biomass Supply Analysis and Logistics model which has successfully modeled the supply logistics of crop residue. The model uses the latest version of "EXTENDSIM" discrete-event simulation software platform to estimate the cost, energy input, and greenhouse gas emissions for the entire operations of forest residue supply system. The developed simulation model can be used as a decision support tool to design a forest residue-based supply logistic system. 
Peter Flynn reviewed how biomass such as agricultural or woody residues can be processed to a variety of useful energy forms such as electricity via direct combustion or gasification and transportation fuel via lignocellulosic ethanol fermentation or Fischer Tropsch synthesis of diesel from biomass-derived syngas. As the scale of processing increases, the delivered cost of field sourced biomass increases due to increasing transportation distances, but the unit cost of processing the biomass decreases due to economies of scale in both capital and operating cost. Because of the competition between these cost factors, biomass processing plants have an optimum size at which output cost is minimized. In this work, they consolidated available data on the above four processing alternatives, adjusting for currency and inflation, and modeled biomass processing for a range of biomass availability (tonnes or GJ per gross hectare, where gross hectares includes the entire geographical area in which the biomass plant is situated) to explore optimum size as a function of delivered cost of feedstock as well as processing cost. The potential benefits if this analysis was discussed. 